\title{
Prognosis significance of HER-2/neu overexpression/amplification in Chinese patients with curatively resected gastric cancer after the ToGA clinical trial
}

\author{
Fei Zhou', Ning Li', Weihua Jiang ${ }^{1}$, Zhaolai Hua ${ }^{2}$, Lin Xia ${ }^{3}$, Qingyi Wei ${ }^{4}$ and Liwei Wang ${ }^{1 *}$
}

\begin{abstract}
Background: HER-2/neu-targeted therapy has been successfully used in advanced gastric cancer, but the role of HER-2/neu in the prognosis of gastric cancer is not yet clear. In this study, we investigated the correlation between HER-2/neu expression and amplification as well as their association with clinic outcomes in patients with curatively resected gastric cancer.

Methods: We constructed tissue microarray blocks containing $>70 \%$ of gastric cancer tissue and matched adjacent normal gastric tissue for 227 patients. Expression of the HER-2/neu protein in these specimens was analyzed using immunohistochemical staining. Amplification of HER-2/neu was also analyzed for the same samples using fluorescence in situ hybridization. Data on clinicopathological features and relevant prognostic factors in these patients were analyzed.

Results: Of the 227 gastric cancer samples, 11.89\% were positive for HER-2/neu overexpression/amplification under the new scoring system. HER-2/neu overexpression/amplification was closely correlated to the Lauren type, degree of differentiation, tumor size and lymph node metastasis. HER-2/neu overexpression/amplification predicted poor survival in univariate analysis but not in a Cox proportional hazards model.

Conclusion: HER-2/neu overexpression/amplification was not an independent predictor for survival in patients with curatively resected gastric cancer.
\end{abstract}

Keywords: FISH, Gastric cancer, HER-2/neu, IHC, Prognosis

\section{Background}

Although the incidence of gastric cancer is decreasing worldwide, it is still relatively high in China with 420,000 newly diagnosed patients each year. The mortality rate of gastric cancer in China ranks third among all cancer deaths, with 320,000 patients for the period of 2004 to 2005 [1]. Although there has been great improvement in the early diagnosis of gastric cancer, in combination with the recent progress of surgical techniques and comprehensive use of chemotherapy and radiotherapy, the 5-year survival rate for gastric cancer remains as low as $20 \%$ to $30 \%$ [2].

\footnotetext{
* Correspondence: yzwlw@yahoo.com

'Department of Oncology, Shanghai First People's Hospital Affiliated

Shanghai Jiaotong University, Shanghai 200080, China

Full list of author information is available at the end of the article
}

Targeted therapy is a new trend in cancer treatment to improve overall survival in patients with cancer. In regard to gastric cancer, molecularly targeted therapy is also gaining status. Antiangiogenic therapy and antiepidermal growth factor receptor therapy have emerged as a new hope [3], especially the anti-HER-2 drug, trastuzumab. According to the ToGA clinical trial reported in 2010 [4], patients with HER-2/neu overexpression receiving chemotherapy and trastuzumab had a significant longer median overall survival of 13.8 months without any additional adverse side effects. Shitara et al. also reported that patients who were HER-2-positive with advanced gastric cancer had a better prognosis than patients who were negative for HER-2 when treated with trastuzumab [5]. All these indicate that the HER-2/neu-

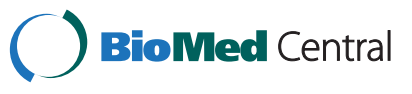


targeted therapy has great potential in improving the treatment of gastric cancer.

Oncogene HER-2/neu was originally discovered in chemically induced rat neuroglioblastomas [6] and is located on chromosome 17q21 and codes for a transmembrane glycoprotein of $185 \mathrm{kD}$. The protein consists of an extracellular ligand-binding domain of 653 amino acids, a single membrane-spanning region of 654 to 675 amino acids, and a cytoplasmic protein tyrosine kinase domain of 675 to 1,255 amino acids. It is one of the members of the human epidermal growth factor receptor (HER) family that includes HER-1 (epidermal growth factor receptor), HER-2/neu, HER-3 and HER-4 [7]. Among these, HER-2/ neu plays an important role in normal development, differentiation and apoptosis of the cell. Gene amplification and overexpression of HER-2/neu have been reported in many cancer types, including that of the ovary [8], lung [9] and prostate [10], in addition to the breast [11]. For example, it has been shown that HER-2/neu overexpression was detected in about $10 \%$ to $34 \%$ of invasive breast cancers and was associated with poor prognosis. Although HER-2/neu is considered an independent prognostic factor for breast cancer, its prognostic role in gastric cancer still remains controversial because several studies have generated conflicting results [12-16].

To assess the association between the status of Her-2/ neu and prognosis of Chinese patients with gastric cancer, we conducted a (we think "the" is better, it means this study) study to examine both expression and amplification of Her-2/neu in tumors of curatively resected gastric cancer and correlated these measurements to the clinicopathological and prognostic outcomes of the patients.

\section{Methods}

\section{Patients and clinicopathological information collection}

A total of 227 patients with gastric cancer from the pathology archives of the Yangzhong People's Hospital were included in this study between 2002 and 2004. All of the patients (except those classified as T1N0M0) had undergone curative surgery and received a similar adjuvant regimen of chemotherapy (5-fluorouracil and cisplatin). Clinicopathological variables including age, sex, histologic type and pathologic stage were collected by reviewing medical charts and pathology records. Among these patients, 157 were men and 70 were women, with an age range between 24 and 79 years old (a median of 60 years old). Tumor sites included 28 antrum, 50 corpus and 149 cardia. Patients were followed from the date of surgery until death, or censored on 31 December 2008, which resulted in a follow-up period of 1 to 108 months (a median of 64 months). The study was approved by our Institutional Ethnic Committee (equivalent to an institutional review board). As this was a retrospective study using archive tissue specimens, the Institutional Ethnic Committee waived the need for written informed consent.

\section{Tissue microarray construction}

In brief, $\mathrm{H} \& \mathrm{E}$-stained sections were made from primary tumor blocks to define two representative tumor regions and adjacent normal gastric tissues. Representative tumor regions were defined as tumor solid areas containing more than $75 \%$ cancer cells without necrosis. Normal gastric tissues were randomly selected adjacent to a tumor with a distance of more than $5 \mathrm{~cm}$, avoiding the bleeding areas. Tumor typing and grading were performed according to Lauren and the World Health Organization (WHO) criteria. All patients with gastric cancer were staged using the seventh edition of the International Union Against Cancer Tumor-Node-Metastasis (TNM) staging system. Tissue cylinders (1.5 $\mathrm{mm}$ in diameter) were then punched from the defined regions of the block using a tissue microarrayer (Gentury, IL, USA) and brought into recipient paraffin blocks. Two sets of three paraffin-embedded tissue microarray (TMA) blocks were made. Sections of the resulting TMA blocks were transferred to glass slides.

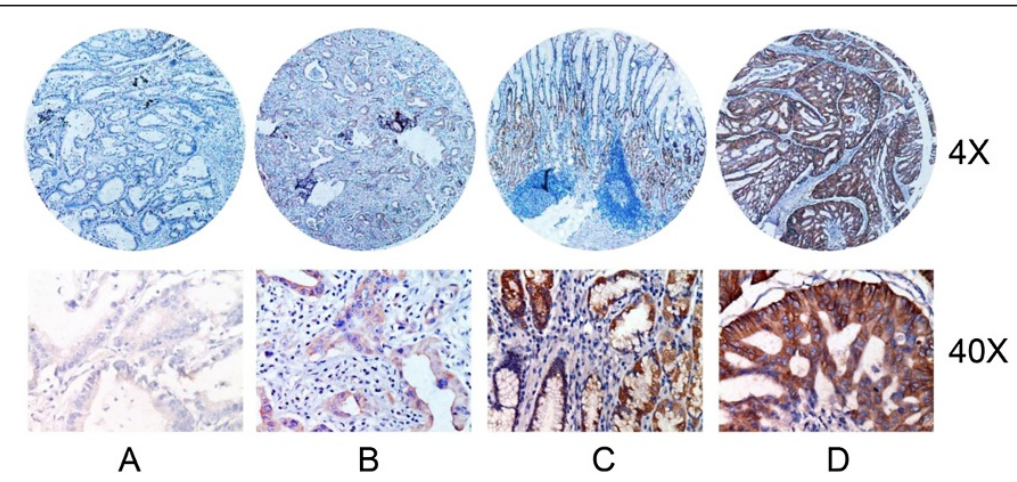

Figure 1 Immunohistochemical staining for HER-2/neu expression in tumor samples from patients with gastric cancer. (A) Membrane staining in normal gastric epithelium for HER-2/neu (0+). (B) Faint membrane staining in $>10 \%$ tumor cells (1+). (C) Moderate complete membrane staining in $>10 \%$ tumor cells (2+). (D) Strong complete membranes staining in $>10 \%$ tumor cells $(3+)$. (H\&E; original magnification, $\times 4, \times 40)$. 
There were a total of two sets of TMA, containing 227 tumor tissue spots and 135 adjacent normal gastric tissue spots each, available for this study (collaborating with Shanghai Biochip, Shanghai, China).

\section{Immunohistochemistry}

Immunohistochemistry (IHC) staining for HER-2/neu was conducted on TMA sections. Formalin-fixed, paraffinembedded sections were dewaxed in xylene and rehydrated through graded alcohol. Endogenous peroxidase activity was quenched by $3 \%$ hydrogen peroxide, then the section was washed in water and the antigen retrieved and placed in citrate buffer. The sections were washed with phosphate-buffered saline, pH 7.2. The primary monoclonal mouse antibody against human HER-2/neu protein (MAB-0198, Maxin Biotech, Fujian, China) was applied for 1 hour in the incubator at $37^{\circ} \mathrm{C}$. Anti-HER-2 antibody (Dako REAL, En Vison, HRP Rabbit/Mouse, Dako, Carpinteria, CA, USA) was then applied. Diaminobenzidine solution was used as a chromogen.

\section{Fluorescence in situ hybridization}

Fluorescence in situ hybridization (FISH) analysis was applied to the sections. Amplification of the HER-2 gene was determined by FISH using a Vysis dual-color, dual-fusion translocation probe set purchased from Abbott Molecular Inc. (DesPlaines, IL, USA). In brief, sections were deparaffinized, dehydrated, and then incubated in 30\% sodium bisulfate for $20 \mathrm{~min}$ at $45^{\circ} \mathrm{C}$. After being washed in $2 \times$ SSC Sodium citrate-Hydrochloric acid Buffer solution \}, slides were treated with proteinase $\mathrm{K}$ at $37^{\circ} \mathrm{C}$ for $25 \mathrm{~min}$. Then hybridization was carried out overnight at $42^{\circ} \mathrm{C}$ in a humid chamber, followed by post-hybridization washes in denaturation solution and $0.1 \% \mathrm{NP}-40$ with $2 \times \mathrm{SCC}$ Sodium citrate-Hydrochloric acid Buffer solution \}at room temperature. Finally, slides were washed and counterstained with $0.2 \mu \mathrm{mol} / \mathrm{L}$ 4'-6-diamidino-2-phenylindole and examined under a confocal laser scanning microscope LSM 510 (Carl-Zeiss, Jena, Germany).

\section{Scoring of immunohistochemistry and fluorescence in situ hybridization}

HER-2 immunostaining was scored using the following scoring system adopted by Hofmann in the ToGA clinical trial: score 0 , no membrane staining or $<10 \%$ of cells stained; $1+$, faint/barely perceptible membranous reactivity in $10 \%$ of cells or higher or reactivity in only part of the cell membrane; $2+$, weak to moderate complete or basolateral membranous reactivity in $10 \%$ of tumor cells or higher; and $3+$, strong complete or basolateral membranous reactivity in $10 \%$ of tumor cells or higher. Scores of 0 and $1+$ were considered negative for HER-2/ neu overexpression, and scores of $3+$ were considered positive. Scores of $2+$ were considered overexpression if
Table 1 Comparison of clinicopathological features according to HER-2 overexpression/amplification

Clinicopathological HER-2 overexpression/amplification

features HER-2/neupositive HER-2/neunegative $(n=27) \quad(n=200)$

\begin{tabular}{ccc}
\hline Age & & \\
$<65$ years & 18 & 96 \\
Sex years & 9 & 104 \\
male & & 139 \\
female & 18 & 61 \\
Lauren & 9 & 118 \\
intestinal & & 49 \\
diffuse & 26 & 33 \\
mixed & 0 & \\
WHO classification & 1 & 24 \\
W/D & & 97 \\
M/D & 9 & 79 \\
P/D & 16 &
\end{tabular}

Tumor size

0.002

$\geq 5 \mathrm{~cm}$

$<5 \mathrm{~cm}$

18

9

0.258

cardia

21

corpus

antrum

Invasion depth

0.322

T1

$\mathrm{T} 2$

T3

Lymph node

0.022

present

20

absent

7

0.320

TNM stage

I

II

III

Vessel invasion

present

416

absent

23

Borrmann

$\begin{array}{ccc}\text { I } & 4 & 26 \\ \text { II } & 17 & 102 \\ \text { III } & 6 & 64 \\ \text { IV } & 0 & 8\end{array}$

M/D: moderately differentiated; P/D: poorly differentiated; W/D: well differentiated WHO: World Health Organization. 


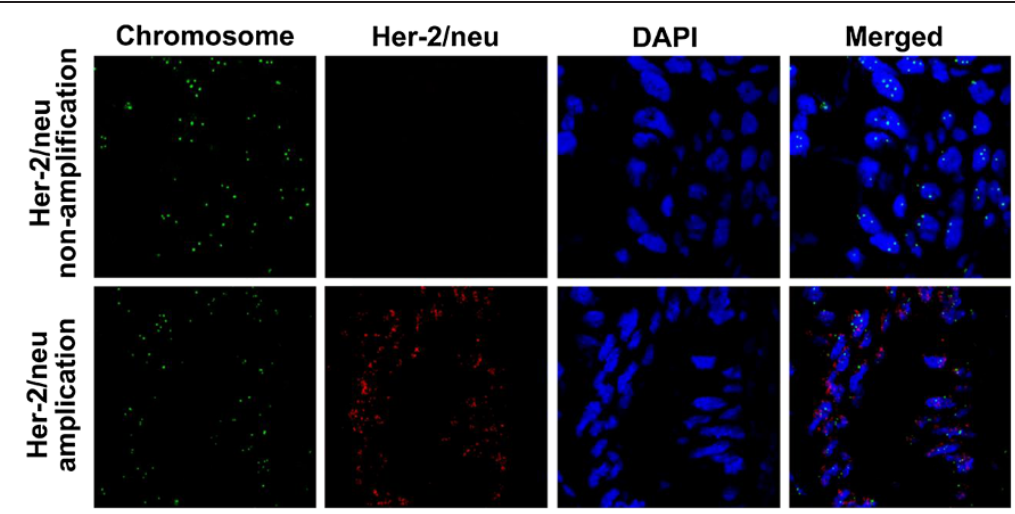

Figure 2 Fluorescence in situ hybridization of HER-2/neu amplification (original magnification, $\times 60$ ).

FISH confirmed amplification [4,17]. Gene amplification was defined as cancer cell nuclei exhibiting a ratio of HER-2/neu to CEP17 (centromeric probe 17) $\geq 2$, or when an HER-2/neu signal cluster was observed.

All samples on the TMA sections from gastric cancers were reviewed by two pathologists independently to determine scores of IHC. For discordant opinions, the samples were re-examined by the two pathologists to achieve a consensus score.

\section{Statistical analysis}

Categorical data were analyzed using $X^{2}$ statistics. The probability of survival by different subgroups was calculated using the Kaplan-Meier method, and statistical significance was analyzed by using the log-rank test. Multivariate analysis was carried out by using the Cox proportional hazards model with adjustment for covariates to identify primary prognostic indicators that were independently associated with survival. All statistics were two-sided, at a significant level of $P<0.05$, by using the SPSS statistical software package for Windows (release 13.0, SPSS, Inc., Chicago, IL, USA).

\section{Results}

HER-2/neu protein expression status and clinicopathological variables in $\mathbf{2 2 7}$ cases of gastric carcinoma

HER-2/neu protein expression in gastric cancer tissues was determined by IHC for 227 patients. As shown in Figure 1, the immunostaining revealed that expression was detectable only in the cell membranes of tumor cells but not in the adjacent normal gastric epithelial cells. Of these 227 tumors, 189 cases $(83.41 \%)$ scored $0 ; 4$ cases (1.75\%) scored $1+; 11$ cases (4.80\%) scored 2+; and 23 cases $(10.04 \%)$ scored $3+$. Among 11 cases of $2+, 4$ cases (36.4\%) were positive for amplification. Therefore, 27 cases (11.89\%) had HER-2/neu overexpression. The correlation between HER-2/neu protein expression levels and clinicopathological variables are summarized in Table 1. Compared with tumors without overexpression, tumors of gastric cancer with HER-2/neu overexpression showed predominantly well- or moderately differentiated histology by the WHO classification $(P<0.05)$ and an intestinal type histology by the Lauren classification $(P<0.05)$. HER-2/ neu overexpression was also associated with tumor size and lymph node metastasis $(P<0.05)$. However, no differences in the expression levels by age, sex, tumor location, invasion depth, TNM stage, vessel invasion or Borrmann type were found for all $(P>0.05)$.

\section{HER-2/neu amplification status in 227 cases of gastric}

\section{carcinoma}

In the FISH analysis, gene amplification was detected in all tumor samples (Figure 2). When the results of FISH and IHC were compared (Table 2), IHC $0+$ or $1+$ samples did not exhibit amplification (0\%), whereas 23 tumors with $3+$ immunostaining all showed amplification (100\%). Nevertheless, among the 11 tumors with $2+$ immunostaining, only showed amplification (36.37\%). There were 27 cases $(11.89 \%)$ of HER-2/neu amplification in the same tumors that had overexpression.

\section{Survival analysis}

Survival analysis was performed on these 227 patients. Patients with tumors with HER-2/neu overexpression/ amplification showed lower 5-year survival rates than those without $(27.3 \%$ versus $42.8 \%, P<0.05)$. In our univariate analysis, Lauren classification, differentiated

Table 2 Correlation between overexpression and amplification for HER-2/neu

\begin{tabular}{|c|c|c|c|c|c|}
\hline \multirow[t]{2}{*}{ FISH } & \multicolumn{5}{|c|}{$\mathrm{IHC}$} \\
\hline & $\begin{array}{c}0 \\
n=189\end{array}$ & $\begin{array}{c}1+ \\
n=4\end{array}$ & $\begin{array}{c}2+ \\
n=11\end{array}$ & $\begin{array}{c}3+ \\
n=23\end{array}$ & $\begin{array}{c}\text { Total } \\
\mathrm{n}=227\end{array}$ \\
\hline No amplification & 189 & 4 & 7 & 0 & 227 \\
\hline Amplification & 0 & 0 & 4 & 23 & 27 \\
\hline Amplification rate (\%) & 0 & 0 & 36.40 & 100 & 11.89 \\
\hline
\end{tabular}

FISH: fluorescence in situ hybridization; IHC: immunohistochemistry. 
Table 3 Univariate and multivariate overall survival analysis for $\mathbf{2 2 7}$ patients with gastric cancer

\begin{tabular}{|c|c|}
\hline Variables & $\begin{array}{r}U \\
\text { 5-year sur }\end{array}$ \\
\hline \multicolumn{2}{|l|}{ Age } \\
\hline$\geq 65$ years & 39 \\
\hline$<65$ years & 41 \\
\hline \multicolumn{2}{|l|}{ Sex } \\
\hline male & 43 \\
\hline female & 34 \\
\hline \multicolumn{2}{|l|}{ Lauren } \\
\hline intestinal & 48 \\
\hline diffuse & 18 \\
\hline mixed & 38 \\
\hline \multicolumn{2}{|l|}{$\begin{array}{l}\text { WHO } \\
\text { classification }\end{array}$} \\
\hline W/D & 63 \\
\hline$M / D$ & 45 \\
\hline P/D & 24 \\
\hline
\end{tabular}

Tumor size

$\geq 5 \mathrm{~cm}$

$<5 \mathrm{~cm}$

Tumor location

cardia

corpus

antrum

Invasion depth

$\mathrm{T} 1$

$\mathrm{T} 2$

$\mathrm{T3}$

Lymph node

present

absent

TNM stage

।

II

III

Vessel invasion

present

absent

Borrmann

।

II

III

IV Univariate

\begin{tabular}{|c|c|c|}
\hline & Multivaria & \\
\hline$P$ & Hazard ratio & $D$ \\
\hline
\end{tabular}

9.3

41.9

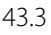

34.3

48.6

18.4

38.2

63.6

45.1

24.7

0.001

21.1

53.9

35.9

50.0

$<0.001$

66.7

29.8

$<0.001$

25.4

64.0

76.1

51.7

220

15.0

43.0

73.3

39.5

32.9

0
Table 3 Univariate and multivariate overall survival analysis for $\mathbf{2 2 7}$ patients with gastric cancer (Continued)

\begin{tabular}{lll}
\hline HER-2 & & \\
overexpression & 27.3 & 0.351 \\
positive & 42.8 & \\
negative & 0.031 & \\
\hline
\end{tabular}

M/D: moderately differentiated; P/D: poorly differentiated; W/D: well differentiated.

histology, tumor size $(\geq 5 \mathrm{~cm})$, invasion depth, lymph node metastasis, TNM stage, vessel invasion and HER-2/ neu overexpression/amplification were all associated with poor survival $(P<0.05)$ (Table 3). A final multivariate Cox proportional hazards model identified Lauren classification, vessel invasion, TNM stage and tumor size $(\geq 5 \mathrm{~cm})$ as bearing prognostic importance $(P<0.05)$; however, HER-2/neu overexpression/amplification was not an independent prognostic factor in this model (Table 3).

\section{Discussion}

Since the publication of the ToGA study, the standard for HER-2/neu overexpression has changed from IHC $2+$ or $3+$ to IHC $3+$ or IHC $2+$ with amplification, which means that conclusions reached before in the literature should be assessed again and could be different according to the new criteria. In our study, we evaluated HER-2/neu overexpression and amplification in 227 curatively resected gastric cancers using the new criteria. We performed IHC and FISH on all the samples and found that all the cases of $3+$ showed amplification, 4 of 11 cases of $2+$ showed amplification, but all the cases of $0+$ and $1+$ exhibited no amplification. Because there was no amplification in IHC $0+$ and $1+$, the cases of tumors with HER-2/neu amplification equals the cases of tumors with overexpression in the present study.

In the literature, there are conflicting reports about the correlation between IHC and amplification. For example, Kim et al. [18] reported that (4\%) of 101 cases scored 1+ had amplification measured by FISH, but Bang et al. [4] reported in the multicenter ToGA trial that the proportion of IHC 0/1+ samples tested positive by FISH in 594 patients was $23 \%$. In our study, we did not find any amplification sign in IHC $0 / 1+$. We think this discrepancy is likely due to sample sizes and ethnic groups included in the reported studies, but other mechanisms may also contribute the discrepancy, such as polysomy 17 chromosome, altered length in the $5^{\prime}$-untranslated region of mRNA of HER-2/neu, some post-transcriptional events, or the HER-2/neu false positivity of the tumors $[19,20]$.

In our study, the rate of HER-2/neu overexpression/ amplification was $11.89 \%$, which fell within the range of 9.3\% to $22.6 \%$ [12,13,15,18,21-23] reported after 2005 using the old scoring system. It was also in the range of 
$6 \%$ to $12 \%$ given by Hsu et al. using the new scoring system [24]; these authors were the first to use the new scoring system in a large-scale experiment, with a reported rate of $6.1 \%$ for HER-2/neu overexpression. The authors attributed their observed low positivity to the new criteria and some other reasons, such as geographic variations, tumor heterogeneity, the employment of different antibodies, and inter-observer variation. However, one important reason must be considered for the variation in the overexpression, which is what Chung et al. [25] found in their screening program for the ToGA: HER-2 positivity rates differed by tumor locations and types, for example, rates were higher in the gastroesophageal junction than in stomach cancer and higher in intestinal than in diffuse or mixed cancer. In the patient group studied by Hsu et al., 16.4\% of patients had a tumor of the gastroesophageal junction and $79.8 \%$ patients had stomach cancer, but $50.2 \%$ had the intestinal type and $49.8 \%$ had a mixed and diffused type, which we think was the direct reason for his low positivity rate of $6.1 \%$. The situation was the opposite for Hofman et al. [17], who had $71.5 \%$ of patients with intestinal type and $28.5 \%$ with mixed and diffused type, with a combined HER-2/neu positivity rate of $13.6 \%$. We had a relatively higher proportion of patients with gastroesophageal junction and intestinal type cancer in our patient groups; we thus had a relatively higher proportion of HER-2 positivity rates.

In our study, we found that HER-2/neu overexpression/ amplification was associated with Lauren type, WHO histological grade, tumor size and lymph node metastasis. For the association of the HER-2/neu overexpression/ amplification with clinicopathological findings, most previous studies reported a higher HER-2/neu overexpression/amplification in intestinal than in diffuse cancers. For example, both Tanner et al. [12] and Barros-Silva et al. [13] reported similar findings. The ToGA [4] study further confirmed the results by screening a much larger sample size. To date, it is not clear why HER-2/neu is so closely associated with intestinal cancer, but a great number of molecular differences by cancer histology have been reported. For example, E-cadherin was reported to be dominantly confined to the diffuse cancer $[26,27]$. Intestinal cancer is usually well differentiated, but diffuse cancer is poorly differentiated, which means that overexpression/amplification of HER-2/neu are consistent with WHO classification and Lauren classification. Yonemura et al. [28] reported that overexpression of HER-2/neu was related to tumor size, invasion depth, lymph node metastasis and TNM stage, whereas Mizutani et al. [29] found that overexpression of HER-2/neu was associated with invasion depth and liver metastasis but not with lymph node metastasis. We believe that the most important reason for differences may be the use of different standards to enroll patients, in addition to selection of tissue samples and the criteria for IHC scoring.

To minimize the impact of staging factor on prognosis analysis, we used patients with curatively resected gastric cancer. In our univariate analysis, overexpression or amplification of HER-2/neu was a prognostic factor but the statistical result for such an association was not present in multivariate Cox proportional hazards model with adjustment of age and sex. In a summary of reported studies on HER-2/neu prognosis after 2005, as shown in Table 4, Park et al. [15] also used patients with curatively resected gastric cancer and adopted the old standard and reached the same conclusion as ours after similar analyses, in which they found HER-2/neu to be a prognostic factor in the univariate analysis but not in the Cox proportional hazards model. Later, Hsu et al. [24] employed the new standard but failed to yield any positive results. Similarly, Begnami et al. [22] also found HER-2/neu amplification to be an independent prognostic factor in univariate log-rank analysis but not in a Cox proportional hazards model.

By contrast, Liu et al. [23] showed that the overexpression of HER-2 predicted poor prognosis in patients with

Table 4 Literature review about the prognosis of HER-2 overexpression or amplification in gastric cancer

\begin{tabular}{|c|c|c|c|c|}
\hline \multirow[t]{2}{*}{ Reference } & \multirow[t]{2}{*}{ N (total/survival analysis) } & \multirow[t]{2}{*}{$\%$ HER-2/neu+ definition } & \multicolumn{2}{|c|}{ Prognostic factor } \\
\hline & & & Univariate analysis/association & Multivariate analysis \\
\hline$[12]$ & $131 / 131$ & $12.2(\mathrm{FISH}+)$ & Yes/two groups & Not done \\
\hline$[15]$ & $182 / 182$ & $15.9(\operatorname{IHC} 2+$ or $3+)$ & Yes/two groups & No \\
\hline $\begin{array}{l}\text { Kim MA } \\
(2007)[18]\end{array}$ & $248 / 96$ & $7.7(\mathrm{FISH}+)$ & Yes/Intestinal type, I stage & Not done \\
\hline$[13]$ & $463 / 256$ & $9.3(\mathrm{FISH}+)$ & Yes/Expansive type & Not done \\
\hline$[21]$ & 1414/582 (section), 598/255 (TMA) & $\begin{array}{l}12.3 \text { (section), } 17 \text { (TMA) } \\
(\text { IHC } 2+\text { or } 3+)\end{array}$ & Yes/Differentiation (W+M) & $\begin{array}{l}\text { No (section)/Yes } \\
\text { (TMA) }\end{array}$ \\
\hline$[22]$ & $221 / 221$ & $15(\mathrm{FISH}+)$ & Yes/two groups & Not done \\
\hline$[23]$ & $217 / 217$ & $11(\mathrm{IHC} 3+)$ & Yes/two groups and intestinal type & Not done \\
\hline [24] & 1036/1036 & $6.1(\mathrm{IHC}+$ or $\mathrm{IHC} 2+$ and $\mathrm{FISH}+)$ & No & No \\
\hline
\end{tabular}

FISH: fluorescence in situ hybridization; IHC: immunohistochemistry; M: moderately differentiated; TMA: tissue microarray; W: well differentiated. 
gastric cancers, but the authors defined IHC $3+$ as overexpression and neglected IHC $2+$ in their statistical analysis. Worth a mention was that Barros-Silva et al. [13], MA Kim et al. [18] and KC Kim et al. [21] all reached a positive conclusion in their subgroup analysis, especially for the study by MC Kim. They did a subgroup OS analysis in differentiated gastric cancer (well- and moderately differentiated) with the largest sample to date (1,414 patients) and found in the Cox model that Her-2/ neu overexpression was a prognostic factor, which perhaps gave us a new perspective to look at Her-2/neu overexpression in gastric cancer. In a time of targeted therapy, how to identify the right target and administrate the right drug to the right patients is a great challenge for both doctors and patients. The ToGA trial led to the conclusion that trastuzumab should be used to treat patients with Her-2/neu overexpression, but according to the above data and analyses, we wonder whether further large studies should be done to refine the right patients for the use of trastuzumab, a drug that is too expensive for every patient to afford in China.

The limitation of this study was the use of microscopy arrays that limited the assessment of HER-2/neu overexpression/amplification to very small portions of the tumor. Although Marx et al. [30] reached the conclusion that HER-2 amplification was highly homogenous in gastric cancer, and even a whole-tissue section cannot be guaranteed to contain all the HER-2/neu overexpression/amplification, it is a fact that intratumoral heterogeneity for HER-2/neu overexpression/amplification was found to be more common in gastric cancer than in breast cancer. Thus, our study may underestimate the overall positivity of HER-2/neu overexpression/amplification in gastric cancer.

\section{Conclusions}

We conclud that HER-2/neu overexpression/amplification was present in $11.89 \%$ of Chinese patients with gastric cancer, and is not an independent prognostic factor for patients with curatively resected gastric cancer.

\section{Abbreviations}

FISH: Fluorescence in situ hybridization; H \& E: hematoxylin and eosin; HER: human epidermal growth factor receptor; IHC: Immunohistochemistry; TMA: tissue microarray; TNM: Tumor-Node-Metastasis; WHO: World Health Organization.
}

\section{Competing interests}

The authors declare that they have no competing interests.

\section{Authors' contributions}

FZ carried out the experiment and data acquisition, and drafted the manuscript. NL helped with the experiment and data acquisition. WJ helped with the literature research. ZH and LX participated in collecting the samples. QW helped with writing, discussion of and editing the manuscript. LW designed the study, and read and revised the manuscript. All authors read and approved the final manuscript

\section{Acknowledgements}

This work was supported by a grant from the Project Sponsored by National Natural Science Foundation of China (No. 81071667) and a grant from the Project Sponsored by Science and technology commission of Shanghai Municipality (No.09DZ1950100). We thank Dr Lei Wang for his technical assistance.

\section{Author details}

'Department of Oncology, Shanghai First People's Hospital Affiliated Shanghai Jiaotong University, Shanghai 200080, China. ${ }^{2}$ Cancer Institute of Yangzhong City, People's Hospital of Yangzhong City, Jiangsu Province 212200, China. ${ }^{3}$ Department of Pathology, People's Hospital of Yangzhong City, Jiangsu Province 212200, China. ${ }^{4}$ Department of Epidemiology, University of Texas MD Anderson Cancer Center, Houston, TX, USA.

Received: 26 August 2012 Accepted: 26 November 2012

Published: 18 December 2012

\section{References}

1. Chen WQ: Estimation of cancer incidence and mortality in China in 2004-2005. Zhonghua Zhong Liu Za Zhi 2009, 31:664-668.

2. Qin $S Q, G X$ : The status quo and new progress in the chemotherapy of the advanced gastric cancer. Chin Clin Oncol 2006, 11:641-652.

3. Meza-Junco J, Sawyer MB: Metastatic gastric cancer - focus on targeted therapies. Biologics 2012, 6:137-146.

4. Bang YJ, van Cutsem E, Feyereislova A, Chung HC, Shen L, Sawaki A, Lordick F, Ohtsu A, Omuro Y, Satoh T, Aprile G, Kulikov E, Hill J, Lehle M, Rüschoff J, Kang YK, ToGA Trial Investigators: Trastuzumab in combination with chemotherapy versus chemotherapy alone for treatment of HER2-positive advanced gastric or gastro-oesophageal junction cancer (ToGA): a phase 3, open-label, randomised controlled trial. Lancet 2010, 376:687-697.

5. Shitara K, Yatabe Y, Matsuo K, Sugano M, Kondo C, Takahari D, Ura T, Tajika M, Ito S, Muro K: Prognosis of patients with advanced gastric cancer by HER2 status and trastuzumab treatment. Gastric Cancer 2012: [Epub ahead of print].

6. Shih C, Padhy LC, Murray M, Weinberg RA: Transforming genes of carcinomas and neuroblastomas introduced into mouse fibroblasts. Nature 1981, 290:261-264.

7. Hung MC, Lau YK: Basic science of HER-2/neu: a review. Semin Oncol 1999, 26:51-59.

8. McKenzie SJ, DeSombre KA, Bast BS, Hollis DR, Whitaker RS, Berchuck A, Boyer CM, Bast RC Jr: Serum levels of HER-2 neu (C-erbB-2) correlate with overexpression of p185neu in human ovarian cancer. Cancer 1993, 71:3942-3946.

9. Hirashima N, Takahashi W, Yoshii S, Yamane T, Ooi A: Protein overexpression and gene amplification of c-erb B-2 in pulmonary carcinomas: a comparative immunohistochemical and fluorescence in situ hybridization study. Mod Pathol 2001, 14:556-562.

10. Ross JS, Sheehan C, Hayner-Buchan AM, Ambros RA, Kallakury BV, Kaufman R, Fisher HA, Muraca PJ: HER-2/neu gene amplification status in prostate cancer by fluorescence in situ hybridization. Hum Pathol 1997, 28:827-833.

11. Kaptain S, Tan LK, Chen B: Her-2/neu and breast cancer. Diagn Mol Pathol 2001, 10:139-152.

12. Tanner M, Hollmen M, Junttila $T$, Kapanen Al, Tommola S, Soini Y, Helin $H$, Salo J, Joensuu H, Sihvo E, Elenius K, Isola J: Amplification of HER-2 in gastric carcinoma: association with Topoisomerase llalpha gene amplification, intestinal type, poor prognosis and sensitivity to trastuzumab. Ann Oncol 2005, 16:273-278.

13. Barros-Silva JD, Leitao D, Afonso L, Vieira J, Dinis-Ribeiro M, Fragoso M, Bento MJ, Santos L, Ferreira P, Rego S, Brandão C, Carneiro F, Lopes C, Schmitt F, Teixeira MR: Association of ERBB2 gene status with histopathological parameters and disease-specific survival in gastric carcinoma patients. Br J Cancer 2009, 100:487-493.

14. Gravalos $C$, Jimeno A: HER2 in gastric cancer: a new prognostic factor and a novel therapeutic target. Ann Oncol 2008, 19:1523-1529.

15. Park DI, Yun JW, Park JH, Oh SJ, Kim HJ, Cho YK, II Sohn C, Jeon WK, Kim BI, Yoo CH, Son BH, Cho EY, Chae SW, Kim EJ, Sohn JH, Ryu SH, Sepulveda AR: HER-2/neu amplification is an independent prognostic factor in gastric cancer. Dig Dis Sci 2006, 51:1371-1379.

16. Terashima M, Kitada K, Ochiai A, Ichikawa W, Kurahashi I, Sakuramoto S, Katai H, Sano T, Imamura H, Sasako M: Impact of expression of human 
epidermal growth factor receptors EGFR and ERBB2 on survival in stage II/III gastric cancer. Clin Cancer Res 2012, 18:5992-6000.

17. Hofmann M, Stoss O, Shi D, Buttner R, van de Vijver M, Kim W, Ochiai A, Ruschoff J, Henkel T: Assessment of a HER2 scoring system for gastric cancer: results from a validation study. Histopathology 2008, 52:797-805.

18. Kim MA, Jung EJ, Lee HS, Lee HE, Jeon YK, Yang HK, Kim WH: Evaluation of HER-2 gene status in gastric carcinoma using immunohistochemistry, fluorescence in situ hybridization, and real-time quantitative polymerase chain reaction. Hum Pathol 2007, 38:1386-1393.

19. Tubbs RR, Pettay JD, Roche PC, Stoler MH, Jenkins RB, Grogan TM: Discrepancies in clinical laboratory testing of eligibility for trastuzumab therapy: apparent immunohistochemical false-positives do not get the message. J Clin Oncol 2001, 19:2714-2721.

20. Bae CD, Juhnn YS, Park JB: Post-transcriptional control of c-erb B-2 overexpression in stomach cancer cells. Exp Mol Med 2001, 33:15-19.

21. Kim KC, Koh YW, Chang HM, Kim TH, Yook JH, Kim BS, Jang SJ, Park YS: Evaluation of HER2 protein expression in gastric carcinomas: comparative analysis of 1,414 cases of whole-tissue sections and 595 cases of tissue microarrays. Ann Surg Oncol 2011, 18:2833-2840.

22. Begnami MDFE, Fregnani JH, Nonogaki S, Montagnini AL, Da Costa WL Jr, Soares FA: Prognostic implications of altered human epidermal growth factor receptors (HERs) in gastric carcinomas: HER2 and HER3 are predictors of poor outcome. J Clin Oncol 2011, 29:3030-3036.

23. Liu W, Zhong S, Chen J, Yu Y: HER-2/neu overexpression is an independent prognostic factor for intestinal-type and early-stage gastric cancer patients. J Clin Gastroenterol 2012, 46:e31-e37.

24. Hsu JT, Chen TC, Tseng JH, Chiu CT, Liu KH, Yeh CN, Hwang TL, Jan YY, Yeh TS: Impact of HER-2 overexpression/amplification on the prognosis of gastric cancer patients undergoing resection: a single-center study of 1,036 patients. Oncologist 2011, 16:1706-1713.

25. Chung H, Bang YJ, Xu JM, Lordick F, Sawaki A, Lipatov O, Lehle M, Pickl M, Rueschoff J, van Cutsem E: 6511 Human epidermal growth factor receptor 2 (HER2) in gastric cancer (GC): results of the ToGA trial screening programme and recommendations for HER2 testing. European Journal of Cancer Supplements 2009, 7:364.

26. Mayer B, Johnson JP, Leitl F, Jauch KW, Heiss MM, Schildberg FW, Birchmeier W, Funke I: E-cadherin expression in primary and metastatic gastric cancer: down-regulation correlates with cellular dedifferentiation and glandular disintegration. Cancer Res 1993, 53:1690-1695.

27. Machado J, Carneiro F, Sobrinho-Simoes M: E-cadherin mutations in gastric carcinoma. J Pathol 2000, 191:466-468.

28. Yonemura Y, Ninomiya I, Ohoyama S, Kimura H, Yamaguchi A, Fushida S, Kosaka T, Miwa K, Miyazaki I, Endou Y, Tanaka M, Sasaki T: Expression of c-erbB-2 oncoprotein in gastric carcinoma. Immunoreactivity for c-erbB-2 protein is an independent indicator of poor short-term prognosis in patients with gastric carcinoma. Cancer 1991, 67:2914-2918.

29. Mizutani T, Onda M, Tokunaga A, Yamanaka N, Sugisaki Y: Relationship of C-erbB-2 protein expression and gene amplification to invasion and metastasis in human gastric cancer. Cancer 1993, 72:2083-2088.

30. Marx AH, Tharun L, Muth J, Dancau AM, Simon R, Yekebas E, Kaifi JT, Mirlacher M, Brummendorf TH, Bokemeyer C, Izbicki JR, Sauter G: HER-2 amplification is highly homogenous in gastric cancer. Hum Pathol 2009, 40:769-777.

doi:10.1186/1477-7819-10-274

Cite this article as: Zhou et al:: Prognosis significance of HER-2/neu overexpression/amplification in Chinese patients with curatively resected gastric cancer after the ToGA clinical trial. World Journal of Surgical Oncology 2012 10:274.

\section{Submit your next manuscript to BioMed Central and take full advantage of:}

- Convenient online submission

- Thorough peer review

- No space constraints or color figure charges

- Immediate publication on acceptance

- Inclusion in PubMed, CAS, Scopus and Google Scholar

- Research which is freely available for redistribution 